\title{
Survey and research on enhancing the effect of college students' mobile learning-------Take Zhaoqing University as an example
}

\author{
Miao-miao Zeng ${ }^{1, \mathrm{a}}$, Yi $\mathrm{Liu}^{2, \mathrm{~b}}$ and Hai-Jian $\mathrm{Hu}^{3, \mathrm{c} *}$ \\ ${ }^{1}$ Education Institute,ZhaoQing University, ZhaoQing, China \\ ${ }^{2}$ Education Institute,ZhaoQing University, ZhaoQing, China \\ ${ }^{3}$ Department of Social Sciences,ZhaoQing University, ZhaoQing, China \\ az.miao.m@163.com, b609323726@qq.comb, 40978352@qq.com \\ *corresponding author
}

\begin{abstract}
Keywords: Mobile learning, mobile devices, learning style, learning effect, survey
Abstract. In order to ascertain the current state of knowledge and research, an extensive review of the literature in M-learning has been undertaken to identify and harness potential factors and gaps in implementation. This article provided a critical analysis of m-learning projects and related literature, presenting the findings of this aforementioned analysis. Based on conducting research of mobile on the students of Zhaoqing University, The research analyzed the status of mobile learning, which is divided into two main parts: the survey of college students on mobile learning, the analysis and discussion of the survey results.
\end{abstract}

\section{Introduction}

With the development of wireless mobile networks and low prices trend, computing devices have become ubiquitous in college campuses. From notebook computers to wireless phones and handheld devices, the massive infusion of computing devices and rapidly improving Internet capabilities have altered the nature of higher education. A new way of learning named mobile learning has emerged. It can break the limits of space and time; it is an emerging learning model and process that requires new forms of teaching, learning, contents, and dynamics between actors.

\section{Overview of mobile learning}

What is mobile learning? Mobile learning (m-learning) is an extension of distance education, supported by mobile devices equipped with wireless technologies. Mobile learning is learning with the help of the mobile computing device learning at any time, any place. Mobile computing devices used in mobile learning must be able to effectively present learning content and provide two-way communication between teachers and learners.

It has been variously defined as "learning by means of wireless technological devices that can be pocketed and utilized wherever the learner's device is able to receive unbroken transmission signals[1]", "learning supported by mobile devices such as cellular(mobile)phones, portable computers, and personal audio players[2],", and "any sort of learning that happens when the learner is not at a fixed, predetermined location, or learning that happens when the learner takes advantage of the learning opportunities offered by mobile technologies[3]."

For college students, mobile learning is a learning style to break through time and space, use the mobile devices (such as mobile phones, tablet PCs)to learn in the classroom, dormitory, school road, when waiting in line, go back to the dormitory and other fragments of time.

Current development of mobile learning in China. In China, the academic research of mobile learning began in 2000. At first, it just concerned on theoretical study [4]. Modern Education Center of Peking University has developed three versions of the mobile education platform in 2004, educational resources production, publishing, browsing platform and educational Semantic Web Platform based on ontology, they carried out some relevant trial practice [5]. In 2006, it said that more than 80,000 
students from Shanghai TV University has become the first batch of beneficiaries of mobile phone remote education. At present, although many colleges and universities have begun to consider the application of mobile learning in instruction, but still at the preliminary exploration stage, the stage of large-scale applications is still on the way.

In the past few years, Stand-alone mobile learning applications are proliferating at an astonishing rate: as of September 2011, the iTunes App store offered 46,340 apps in the education category. With the development of mobile education resource, many universities have been building their own WAP site of education and researching and optimizing their mobile learning platform. In the information age, mobile learning as a new approach of learning will inevitably bring an education revolution, which incredibly increases student's knowledge.

However, now there are several critical problems in mobile learning of college student. First, the $\mathrm{p}$ resent situation of development does not match with the rapid development of device and network. College students met with "soft bottleneck" of learning strategies and obsorbing knowledge. Second ly, many college students lack the awareness of the concept of mobile learning. For instance, some st udents study without any learning purpose and plan; instead, those students just want to kill time. Fin ally, many students lack the strategies of mobile learning management, sources researching, and auto nomous learning. In addition, the contents of mobile learning have not enough proper elaborate desig n.

\section{The design of College Students' mobile learning survey}

Survey Purpose. Zhaoqing University is a public full-time undergraduate university, founded in 1970. It is located in Zhaoqing City, Guangdong Province.The full-time students in school is 24893 in 2015.With the emergence of new learning style, college students at Zhaoqing University have changed their learning styles as well; they are no longer just accepting the traditional school education. In order to further understand current state of mobile learning in higher education, such as the reasons for college students to choose mobile learning, the use frequency, resources, results, etc., a survey on the "College Students' mobile learning" was carried on to collect data to analysis the current situation of the students at Zhaoqing University more objectively, explore strategies to improve the effect of mobile learning.

Survey audience. The questionnaire survey is for all students at the Zhaoqing University, mainly through Internet to distribute.175 pieces of questionnaires were returned, 175 copies were valid. Among them, the proportion of men and women in each grade is appropriate. The number of boys and girls surveyed were 90 and 85; there are 34 freshmen, 43 sophomores, 48 juniors and 50 seniors.

Survey content. Well-designed questionnaires according to the purpose of the survey make sure that the problem has a strong correlation with the problem and it has moderate number of problems. The questionnaire contains 21 questions, including 17 multiple-choice questions, three multiple-choice questions (more than one answer), and an essay question. The content of the questionnaire includes many aspects, including the equipment, time, frequency, use place and way of the college students to carry on the mobile learning.

\section{The analysis of the survey results}

Based on the data of surveys, we analyzed the results from several aspects: the selection reasons, equipment used the influence factors of learning effects, problems encountered and the expectations to mobile learning.

Devices and apps used for mobile learning. According to the survey results, the most commonly used mobile devices are mobile phones, accounting for $92.02 \%$, tablet PCs and Kindle electronic readers are $3.68 \%$ and $0.61 \%$. The powerful function of the mobile phone has influenced the learning style of learners deeply. Some people say, do remember to bring mobile phones even forget the wallet when you go out. Secondly, small size and easy to carry are the important factor in favorite elections. 
As Figure 1 shows, students use various mobile apps extensively in their personal lives, with the most frequent use reported for apps that let them check social networking sites, listen to music, and photography. The app of education and productivity are used the least, accounting for only $14.9 \%$ and $11 \%$.

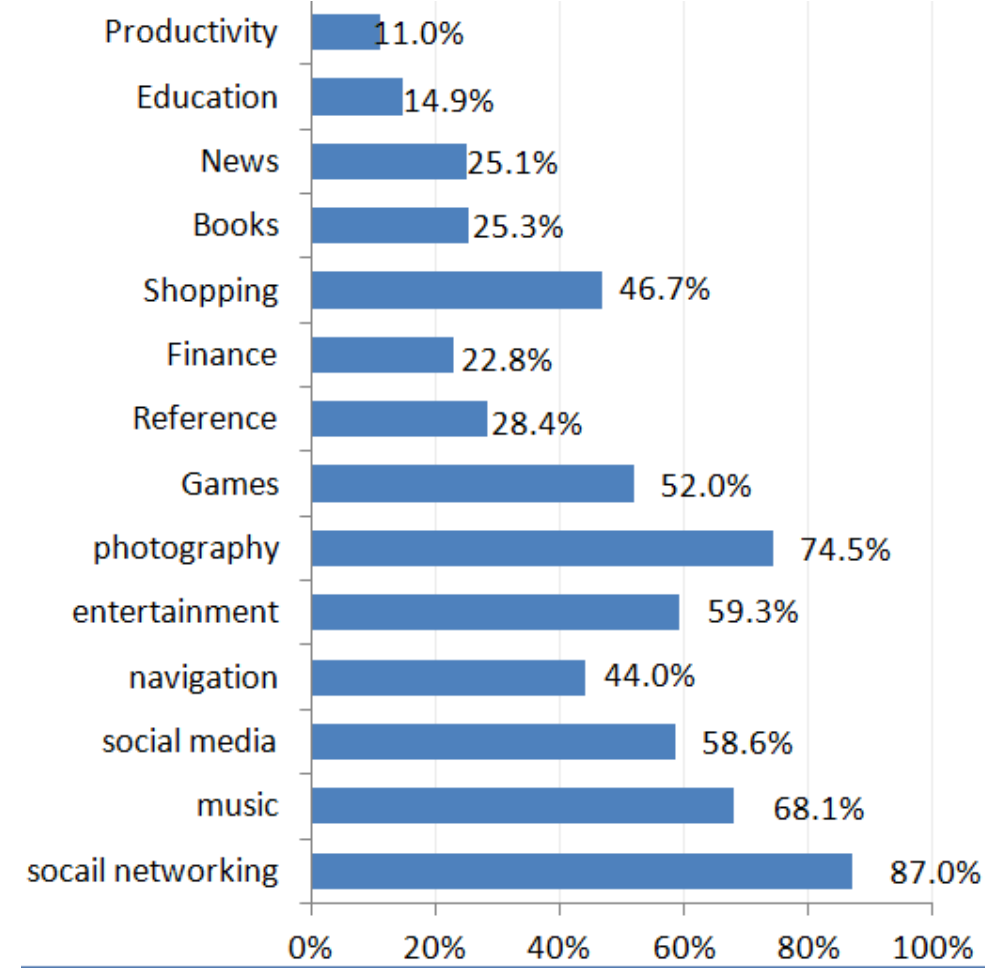

Fig.1. The statistics of most popular app categories of personal use

We asked students about the benefits of using mobile apps/devices for academic purposes. Using a 5-point Liker scale from strongly agree to strongly disagree, students agreed or strongly agreed that using apps and devices. The result is: Makes it easier to access coursework (66 percent), increases communication with other students (69percent), increases communication with instructors (50 percent), increases my knowledge in my field of study (38 percent), improves my quality of work (27percent), and Increases motivation to complete coursework (33 percent).

Reasons for college students to choose mobile learning. There are a variety of reasons for college students to study by mobile learning; its specific distribution is shown in Figure 2. From the picture, it showed that the "rich resources on the Internet" is the main reason for college students to choose mobile learning, accounting for $80.9 \%$, with a mobile device, you can take a library to go out, anything you do not understand, you are interested in, you want to learn, you can consult at anytime and anywhere. Secondly, "the mobile device carried conveniently"accounted for $72.3 \%$, compared with bulky books; compact size of the mobile device has great advantage. The trend of the times and ubiquitous accounted for $46.6 \%$, also the important reasons for the choice of mobile learning.

Factors affected mobile learning effect. When learning, everyone has different problems, resulting in different study effect from person to person. As showed in Figure 3, among them, eye fatigue, $68.1 \%$ of investigator felt the small screen of a mobile device viewing lead to eye fatigue easily; Secondly, "content is too miscellaneous" accounted for $76.1 \%$. When we encounter difficulties, we used to use the search engine to search for answers, sometime, we can't search out the answers we want, or we need to spend a lot of time and energy selecting the refining. These all make the learning effect slashed. Another problem is the limited mobile traffic, accounting for $52.8 \%$, typically opens a web page you need to spend a lot of traffic.

People usually take mobile learning in dormitory, in classroom; many students reflected that it is very difficult to concentrate on learning. Mobile learning is without the teacher's supervision and help, 
which requires independence and self-control more. In addition, the mobile device itself will be a variety of problems, such as insufficient power, low battery, crash and so on.

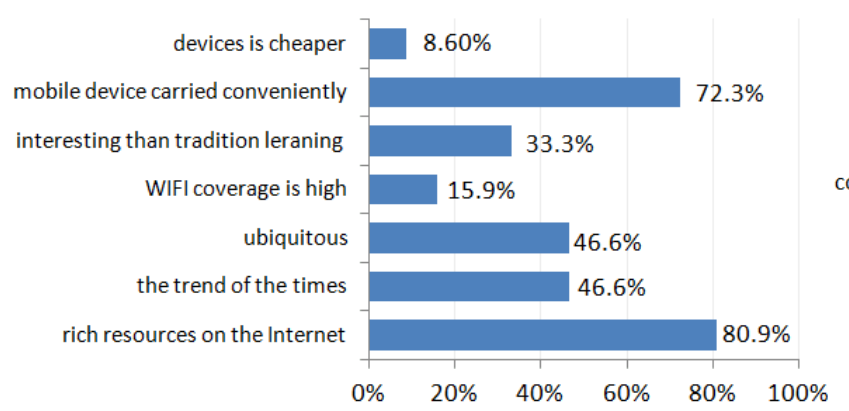

Fig.2. the statistics of reasons for college students to choose mobile learning

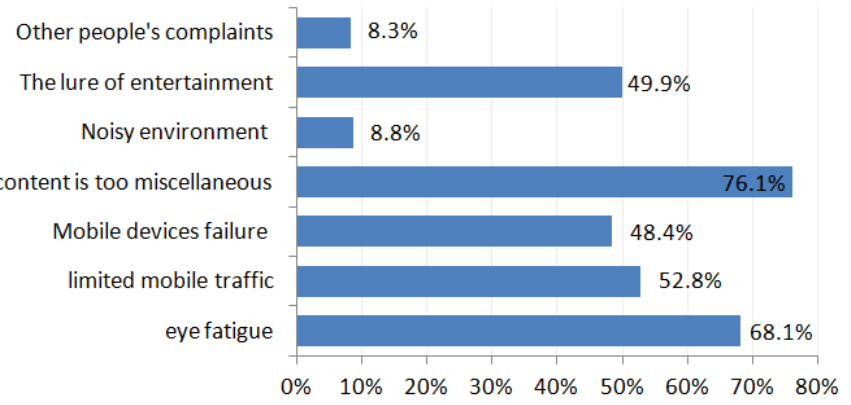

Fig.3.The statistics of factors affected mobile learning effect

\section{Discussions}

Mobile learning is personalized, learner-centered, situated, collaborative, ubiquitous and contextual [6]. Although it still exists many problems, but the existence is reasonable, when there is a problem solved one by one, the effect of College Students' mobile learning will be enhanced; the ranks of mobile learning will add more fresh blood.

Improve the mobile learning device and hardware facilities. Different from books, mobile learning devices are electronic products, which will inevitably produce some radiation. Eye fatigue, the data processing ability is not strong, the storage capacity is low, and these are all need to be considered [7].

Now, Wireless communication networks are moving to broadband capabilities with $3 \mathrm{G}$ and now $4 \mathrm{G}$ protocols coming online. The power of mobile devices is growing along with that of the networks. Student mobile device ownership and use for coursework is increasing. Although cost and device ownership still raise concerns, the survey results indicate that a lack of technical support is the top reason that students do not want instructors to use mobile apps or devices in their coursework.

Improve the college students' ability of mobile learning. As the results of survey showed that part of the respondents has some misunderstanding and lack of understanding of mobile learning way. Most people are lack of courage to try and explore. Someone think mobile learning is similar to traditional way of learning. It will be difficult to learning with mobile devices, most of the case, they don't know how to start and enhance the effect of learning.

As a new way of learning, we must improve the understanding of college students on mobile learning. First of all, schools and teachers should step up publicity about the dynamics of mobile learning, we can give students a detailed acknowledge of the origin, development process of mobile learning, and the situation of foreign countries .Secondly, the school should actively carry out more practice, such as flipped classroom, Blended-learning, Mooc and so on, attracting more student's participation, increasing their perception of mobile learning experience, and encouraging them to practice.

Finally, appropriate pedagogical support is based on a good understanding of students' mobile use habits and needs. To select apps that students already use (and thus lower technical support needs), instructors can examine the 2014 report for details about the most popular app categories among students. Instructors should also consider students' needs by asking them for feedback about the current mobile environment. By catering to student needs and offering matching services, instructors will see more value added to mobile devices, which can increase device ownership and user engagement.

Develop more high quality learning resources. Existing mobile learning resources are rich, but it cannot fully meet the needs of learning. We can develop more suitable mobile learning resources from the following aspects. 
Clear navigation. the learning content of mobile learning resources should be concise, which needs to abandon the irrelevant information, arrange the main content in the most prominent position, the design of interface navigation should be clear and easy to operate, in order to make up for the shortcomings of hardware.

Standardization. The development of resources needs to meet the standard of uniform resources, and can be shared, migrated and saved in different platforms.

Form diversification. Resources should include a variety of media forms, such as text, video, audio, animation, etc. The quality and clarity of resources, suitable media formats should be ensured as well.

Interactivity. The development of mobile learning resources should also pay attention to the interactive function, and to achieve the timely detection and feedback of various problems in the learning process by improving the interaction of resources [8].

Enhance the interactive function of mobile learning. Due to the technical limitations of mobile devices and hardware facilities, a major bottleneck from the student_spoint of view for our current application was the user-interface. While interaction is the core part of learning process.

Interaction between learners and the operating interface. It needs to take full account of the student's operational interaction when design the interactive mobile learning environment, and at the same time provides relevant guidance and training of interface operation for the learners timely [9]. Once the problem of the operation interface was solved, it not only facilitates the operation of the learners, but also greatly increases learners' interest of mobile learning.

Interaction between learners and instruction content. Some scholars consider that the interaction between the learners and the instruction content is a kind of information exchange, we divide it into knowledge information and emotional information, its concrete expression is: Learners and learning resources, and the interaction with other learners and teachers [10]. If there is no interaction in the process, the problems encountered cannot be resolved. That will result in difficulty of improving the effectiveness of mobile learning.

Interaction between learners and learning situation. The essence of learning is a kind of social practice, which is a process of interaction with others and environment. In mobile learning, the interaction with various situations can help the learners' cognitive activities.

Strengthen the teacher's instructional ability of mobile learning. During the mobile learning, uncertainty of time and place dispersed learners' attention. Therefore, it is urgent to strengthen the guidance and supervision of College Students' mobile learning. Teachers can guide students by teaching activities in the classroom and students can also actively apply to the class, strengthen communication between teachers and students, In order to strengthen the guidance and supervision of College Students' mobile learning.

Although some instructors are comfortable with these emerging technologies, others will need pedagogical support and professional development to better utilize them. Instructional designers and specialists can offer instructors pedagogical support by walking beside them as they outline their learning goals and teaching strategies. Once the outline is established, decisions about mobile technology's relevance to a course can be made. Mobile technology should be used only if it can support student learning and enhance the curriculum during learning experiences. Instructional designers can play a key role in this journey by connecting instructors to checklists, searches, and best practices.

Further, institutions can curate well-designed pedagogical support materials into professional development courses and training materials. Such courses can be designed to meet the needs of instructors, who have diverse knowledge levels about the topic. Modular courses, in which instructors can pick and choose different course or take the modules in succession, can be designed with enough flexibility to accommodate instructors regardless of their foundational knowledge level. 


\section{Conclusions}

As a new way of learning, in the rapid development of modern technology, the mobile learning gradually integrated into the life of college students, students can carry out ubiquitous learning so that the fragment time has played the greatest value. Although it seems inevitable that m-learning will soon be an essential extension of e-learning, this transition will not occur over night. Even though mobile technologies are more pervasive in education today, we should always ask the pedagogical question: Is mobile technology necessary to support students in reaching the intended learning outcomes? It's not clear where mobile learning technology and applications will go, but as the factors set forth in this bulletin suggest, it will be disruptive, explosive, and game changing when it hits its stride. We firmly believe that mobile learning will not be a flash in the pan. It will be a brand new appearance for each student in the future.

\section{Acknowledgements}

This research is supported by Foundation for Distinguished Young Talents in Higher Education of Guangdong, China (WYM10107)

\section{References}

[1] Mohamed Osman M. El-Hussein and Johannes C. Cronje, , Defining Mobile Learning in the Higher Education Landscape, Educational, Technology\&Society, $13 \quad$ (3),2010,12-21. http://www.ifets.info/journals/13_3/3.pdf

[2] Mike Sharples,Josie Taylor, and Giasemi Vavoula,A theory of Learning for the Mobile Age",in Sag Handbook of Elearning Research(London:sage,2007),221-247

[3] Andrew Brasher and Josie Taylor,development of a research plan for use of ambient technology to test mobile learning theories, in mobile learning anytime everwhere:A book of papers from MLEARN 2004,eds,Jill Attewell and Carol Savil-Smith,2004,33-37

[4] Zhuting Wu, Research on the current situation of College Students' mobile learning , Nanchang University, 2009,12-22 in Chinese

[5] Jun Wang, Research on the application of mobile learning in Colleges and Universities, Electric Power Education in China, 2013(8) in Chinese

[6] Sharples, Taylor,and Vavolula,"a theory of learning for the Mobile Age,223

[7] Information on http://www.doc88.com/p-9307125091994.html , 2015,4

[8] Information on http://www.yidongxuexi.com/a/14777.html.2014,9

[9] Adkins, The worldwide Market for Mobile Learning products and services,9-12

[10]Clark N.Quinn,the Mobile Academy(san Francisco:John Wiley\&Sons,2012),1-6 